
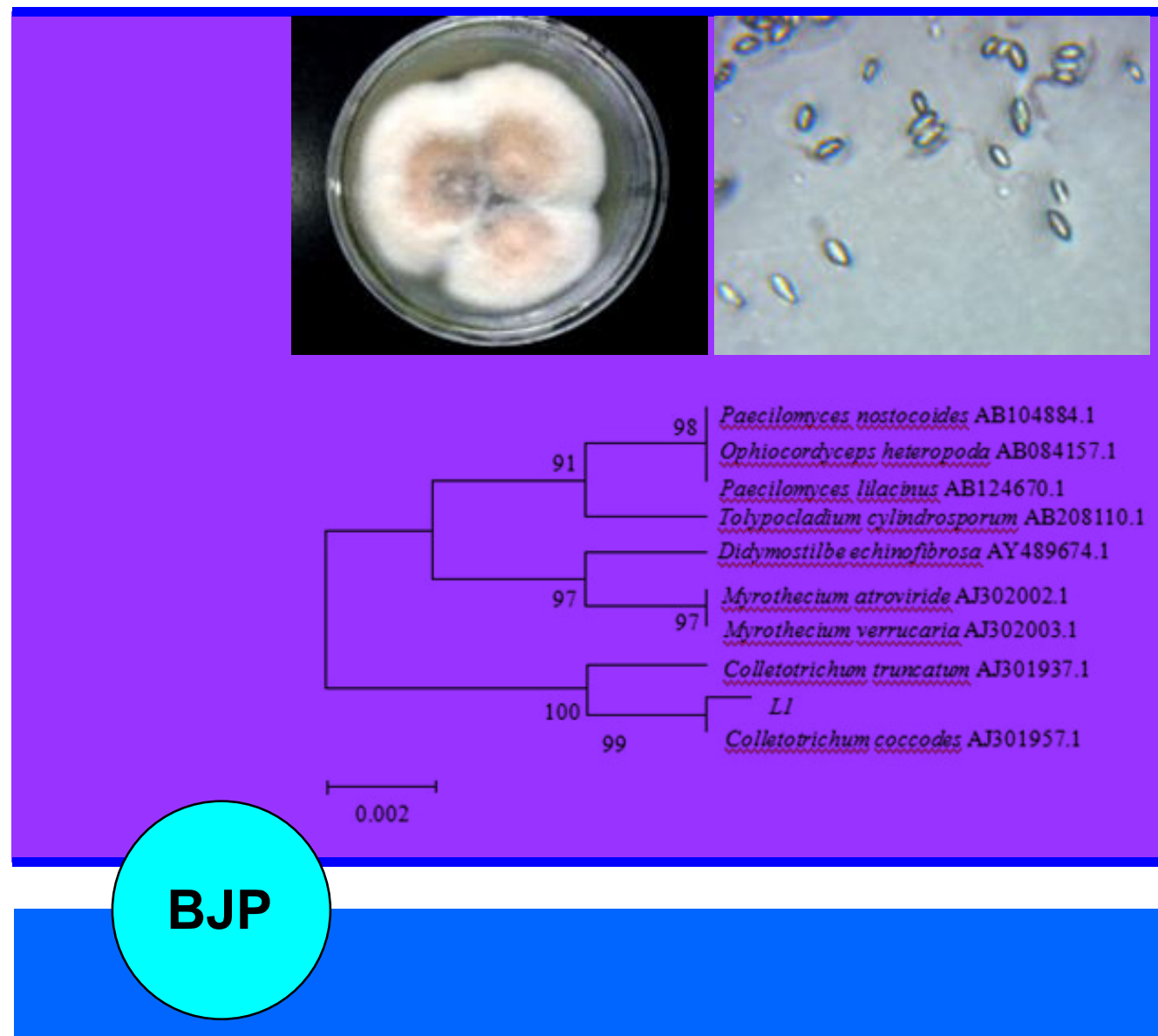

Bangladesh Journal of Pharmacology

Research Article

Antimicrobial assay of endophytic fungi from Rumex madaio and chemical study of strain R1 


\title{
Antimicrobial assay of endophytic fungi from Rumex madaio and chemical study of strain R1
}

\author{
Xuelian Bai', Ronglu Yu², Mingzhu $\mathrm{Li}^{2}$ and Huawei Zhang \\ ${ }^{1}$ College of Life and Environmental Sciences, Hangzhou Normal University, Hangzhou 310036, China; ${ }^{2}$ School of \\ Pharmaceutical Sciences, Zhejiang University of Technology, Hangzhou 310014, China.
}

\begin{tabular}{|c|c|}
\hline \multicolumn{2}{|l|}{ Article Info } \\
\hline Received: & 29 May 201 \\
\hline Accepted: & 12 June 2019 \\
\hline Available Online: & 7 August 2019 \\
\hline \multicolumn{2}{|c|}{ DOI: 10.3329/bjp.v14i3.41598 } \\
\hline \multicolumn{2}{|c|}{$\begin{array}{l}\text { Cite this article: } \\
\text { Bai X, Yu R, Li M, Zhang H. Antimi } \\
\text { crobial assay of endophytic fung } \\
\text { from Rumex madaio and chemica } \\
\text { study of strain R1. Bangladesh J Phar } \\
\text { macol. 2019; 14: 129-00. }\end{array}$} \\
\hline
\end{tabular}

\begin{abstract}
In order to search more antimicrobial natural products for new drug discovery, bioassay and chemical investigation of endophytic strains from Rumex madaio were carried out. Six fungal strains (numbered as L1, L6, L9, L10, R1, R2) were successfully isolated and their antimicrobial effects on three human pathogens, Escherichia coli, Staphyloccocus aureus and Candida albicans, were evaluated. The results indicated that ethyl acetate extracts of fermentation broth of these strains had no potent antimicorbial activity against E. coli and C. albicans while strains L1 and R1 had stronger inhibitory effects on S. aureus. On basis of morphological characteristics and $18 S$ rRNA sequence analysis, strains L1 and R1 were respectively classified as Colletotrichum and Fusarium geni. The chemical study of strain R1 led to isolation of two known antimicrobial agents, dibutyl phthalate (1) and beauvericin (2).
\end{abstract}

\section{Introduction}

Endophyte, one of special microorganisms, resides in the intracellular or intercellular area of healthy plant tissues during their periods of life or the whole (Zhang et al., 2006; Zhang et al., 2018). In this symbiotic system, host plants and endophytes maintain a win-win relationship between species. Host plants offer endophytes with essential nutrients for their growth, while endophytes promote the growth and chemical defense of host plants by producing beneficial metabolites (de Siqueira et al., 2011). Endophytes can dwell in almost all vascular plants (Zheng et al., 2016). Several evidences indicate that endophytic fungi are a species of abundant sources of natural products with diverse chemical structures and bioactivities, such as antimicrobial effect, anti-insect, antioxidant, anti-cancer, antineoplastic, cytotoxic, and so on (Akay et al., 2014; Zhou et al., 2014a; Zhou et al., 2014b; Li et al., 2015; Wang et al., 2016; Liu et al., 2017; Rani et al., 2017; Dhankhar et al., 2013). Moreover, endophytic microbes have the potential capability to produce the same and/or similar bioactive chemicals which are originally detected in their hosts, such as camptothecin, diosgenin, ginkgolide $\mathrm{B}$, huperzine A, hypericin, podophyllotoxin, taxol, vinblastine, and vincristine (Zhang et al., 2014a). So, endophytic microbe could service as an alternative source to make valuable natural products (Yadav et al., 2014).

Rumex belongs to the family of Polygonaceae and possesses about 200 species of annual, biennial, and perennial herbs including Rumex madaio Makino, $R$. obtusifolius L., R. chalpepensis Mill., R. japonicus Houtt., $R$. patientia L., R. nepalensis Spreng and so on. The root and rhizome of $R$. madaio, was a historic medicine for the treatment of hepatitis and skin diseases (Islam and Abay, 2013). Pharmacological study had shown that this medicinal plant has a broad spectrum of biological properties, including antimicrobial, hemostasis, hypoglycemic action, anti-inflammatory and cytotoxic effect (Zhang et al., 2014b). Up to now, however, no literature about biology and chemistry of its endophytic microbes 
had been reported. As part of an ongoing effort to characterize medicinal plant-derived endophytes and their functional metabolites (Zhang et al., 2012; Zhang et al., 2016), isolation of endophytic strains from $R$. madaio and evaluation of antimicrobial effects of their culture extracts were carried out in this study as well as chemical investigation.

\section{Materials and Methods}

\section{Material}

The healthy plant collected from the coast of Putuo Island (Zhoushan, China) was identified by Prof. Bin Wu (Zhejiang University) and used for endophyte isolation within 48 hours after harvest. The specimen (HZNU-201606) was deposited at the College of Life and Environmental Sciences, Hangzhou Normal University. Three testing human pathogenic strains, Escherichia coli AB94012, Staphyloccocus aureus AB2010021, Candida albicans AY204006, were obtained from the China Center for Type Culture Collection. All chemicals used in this work were of analytical grade.

\section{Isolation of endophytic strain}

Isolation of endophytic strain was immediately carried out within 24 hours after harvest. Fungal endophytes were separated from leaves and roots according to our reported procedure (Zhang et al., 2012). Firstly, leaves and roots were washed with running tap water followed by sterilizing with $75 \%$ ethanol for $1 \mathrm{~min}$ and $2.5 \%$ sodium hypochlorite for $10 \mathrm{~min}$, then rinsed in sterile water for three times and cut into several segments with one centimeter in length and width using aseptic surgical blades. Then each segment was inserted in potato dextrose agar medium in petri plates supplemented with $200 \mu \mathrm{g} / \mathrm{mL}$ ampicillin and $200 \mu \mathrm{g} /$ $\mathrm{mL}$ streptomycin and incubated at $28^{\circ} \mathrm{C}$ until the mycelium or colony originating from the newly formed surface of the segments appeared. If a lot of hypha came out, the mycelia of fungal strain were further purified and transferred to other petri plates at the same condition. Another segment of the same specimen without surface sterilization was cultured as a negative control to check the presence of contaminated microbes on the segment surface. Up to six purified endophytic strains were obtained and respectively numbered as L1, L6, L9, L10, R1, R2, and transferred to potato dextrose agar slants separately and were kept at $4^{\circ} \mathrm{C}$ after being cultured at $28^{\circ} \mathrm{C}$ for 7 days.

\section{Identification of bioactive strain}

All purified endophytic strains were subjected to antimicrobial assay. Taxonomic assignment was only deployed on bioactive endophytic strains with potent antimicrobial effects on basis of morphological properties and $18 S$ rRNA sequence analysis according to the methods developed (Santos et al., 2012; de Siqueira et al., 2017). $18 S$ rRNA fragments of bioactive strains were obtained by amplification of genomic DNA using forward primer NS1-GTAGTCATATGCTTGTCTC and reverse primer NS6-GCATCACAGACCTGTTATTGCCTC. Their sequences were analyzed using standard nucleotide BLAST software of NCBI and phylogenetic tree was built using MEGA 6.0 adjacency method (Kumar et al., 2008).

\section{Preparation of crude extract}

Six strains were separately cultured on PDA at $30^{\circ} \mathrm{C}$ for 5-7 days. A balanced amount of fungal colony was transferred to the culture broth in a $500 \mathrm{~mL}$ Erlenmeyer flask, which contained $300 \mathrm{~mL}$ sterilized potato dextrose broth and salted PDB ( $3 \%$ sea salt) followed by shaking at $200 \mathrm{rpm}$ for $7-10$ days at $30^{\circ} \mathrm{C}$. After fermentation, the mycelium and the culture broth were separated by centrifugation at 4,000 rpm for $10 \mathrm{~min}$ at $4^{\circ} \mathrm{C}$. The filtrate was extracted twice with ethyl acetate (Merck). The upper solvent was evaporated at $25^{\circ} \mathrm{C}$ in vacuum to yield the crude extract. The crude extract was reserved at $4^{\circ} \mathrm{C}$. Each extract was kept in a vacuum drier for 3 days and dissolved in dimethyl sulfoxide (DMSO, Merck) before antimicrobial test. The final concentration of each crude extract were respectively $0.1,1,10 \mathrm{mg} / \mathrm{mL}$.

\section{Antibacterial test}

The antibacterial assay was conducted on double plate according to agar dilution method (Wang, 2009). Strains E. coli and S. aureus were respectively transferred into one 250-mL Erlenmeyer flask. Each flask contained 100 $\mathrm{mL}$ sterilized Luria-Bertani medium and incubated at $37^{\circ} \mathrm{C}$ on a rotary shaker at $180 \mathrm{rpm}$ for 24 hours. About $10 \mathrm{~mL}$ of the melted water agar medium was poured into a Petri dish $(\Phi=90 \mathrm{~mm})$ followed by laid with five stainless cylinders (Oxford cup, $\Phi=6 \mathrm{~mm}$ ) equidistantly. After that, $200 \mu \mathrm{L}$ of cultured bacterium was mixed with $200 \mathrm{~mL}$ of fresh nutrition agar medium, and then add it to the solidified water agar medium. After cooling, Oxford cup was removed and $100 \mu \mathrm{L}$ of sample was add to each hole. Ampicillin sodium (30 $\mu \mathrm{g} /$ disk, Amresco) was used as the positive control while DMSO was the negative control. Then the plates were incubated at $37^{\circ} \mathrm{C}$ for 24 hours. All tests were carried out in triplicate and the antibacterial activity was expressed as the average value of inhibition diameters ( $\mathrm{mm})$, which the sizes are measured from the edge of the disk to the end of the clear zone.

\section{Antifungal test}

Antifungal assay was also carried out using the same approach described above. Pathogenic strain C. albicans was transferred into one $250 \mathrm{~mL}$ Erlenmeyer flask. Each flasks had $100 \mathrm{~mL}$ sterilized PDB and incubated at $28^{\circ} \mathrm{C}$ on a rotary shaker at $180 \mathrm{rpm}$ for 48 hours. Potato dextrose agar was used as the upper medium layer of 
the testing plate. Amphotericin B (30 $\mu \mathrm{g} /$ disk, SigmaAldrich) and DMSO were respectively used as positive and negative controls. The diameter of inhibition zone (in $\mathrm{mm}$ ) was measured to evaluate anti-fungal effect. All tests were performed in triplicate.

\section{Extraction and isolation of secondary metabolite}

The fresh mycelium of strain R1 grown on potato dextrose agar plates for 7 days was inoculated into 250 $\mathrm{mL}$ conical flasks containing $100 \mathrm{~mL}$ of PDB medium (Zhang et al., 2014a). After 3 days cultivation at $28^{\circ} \mathrm{C}$ on a rotary shaker at $200 \mathrm{rpm}$, the seed culture $(10 \mathrm{~mL}$ for each flask) was transferred into $500 \mathrm{~mL}$ conical flasks containing $200 \mathrm{~mL}$ of Czapek's medium composed of sucrose $(30 \mathrm{~g} / \mathrm{L}), \mathrm{NaNO}_{3}(3 \mathrm{~g} / \mathrm{L}), \mathrm{K}_{2} \mathrm{HPO}_{4}(1 \mathrm{~g} / \mathrm{L}), \mathrm{KCl}$ $0.5 \mathrm{~g} / \mathrm{L}, \mathrm{MgSO}_{4} \cdot 7 \mathrm{H}_{2} \mathrm{O}(0.5 \mathrm{~g} / \mathrm{L}), \mathrm{FeSO}_{4}(0.01 \mathrm{~g} / \mathrm{L})$, and $\mathrm{H}_{2} \mathrm{O}$ (added to $1000 \mathrm{~mL}$ ) followed by shaking at 200 rpm at $28^{\circ} \mathrm{C}$ for 7 days. The fermented whole broth was filtered through gauze to remove mycelia. The filtrate (approximate $30 \mathrm{~L}$ ) was extracted two times with ethyl acetate in the ratio of 1:1 (v/v). Evaporation of the solvent from the extract in vacuo yielded a crude residue (5.5 g)

The afforded extract was dissolved in methanol followed by filtration and subjected to fast separation on a HPLC apparatus (Water D600) equipped with a preparative column (Phenomenex Gemini-NX C18, 50 $\times 21.2 \mathrm{~mm}, 5 \mu \mathrm{m})$ to afford six fractions F0-F5 using the method described before (Zhang et al., 2017). Then the antimicrobial fraction F4 (0.1547 g) was further separated by semipreparative HPLC with acetinitrile/water $(72: 28, \mathrm{v} / \mathrm{v})$ to give compounds $1\left(35 \mathrm{mg}, \mathrm{t}_{\mathrm{R}}=13.2 \mathrm{~min}\right)$ and 2 (75 $\mathrm{mg}, \mathrm{t}_{\mathrm{R}}=18.0 \mathrm{~min}$ ) (Figure S1).

\section{Structure analysis of compounds 1 and 2}

All NMR spectra of compounds 1 and 2 were measured in $\mathrm{CDCl}_{3}$ on a Bruker DRX-500 instrument. Their ESIMS data were record on a Mariner Mass 5304 spectrometer and melting points were measured using an uncorrected XT-4 apparatus (Figure S2-8).

\section{Antimicrobial assay of compounds 1 and 2}

Antimicrobial activity was assessed by the microbroth dilution method in 96-well culture plates according the procedure developed by our lab (Zhang et al., 2016). All test compounds were dissolved in DMSO $(100 \mu \mathrm{g} \mathrm{mL}$ 1). Ampicillin and amphotericin B (Sigma-Aldrich) were the positive controls and DMSO was used as the negative. Antibacterial activity was assessed by the microbroth dilution method in 96-well culture plates. The test compound was initially made up to $100 \mu \mathrm{M}$ in DMSO. The testing pathogens E. coli and S. aureus were incubated in Luria-Bertani medium for 24 hours at $37^{\circ} \mathrm{C}$ and $C$. albicans was cultured in the potato dextrose broth for 48 hours at $28^{\circ} \mathrm{C}$ at $150 \mathrm{rpm}$. Spores of different microorganism concentrations were diluted to approximately $1 \times 10^{6} \mathrm{cfu}$ with stroke physiological saline solution. $20 \mu \mathrm{L}$ of sample was added to 96-well microplates. Serial dilutions were made in the 96-well round-bottom sterile plates, and then the fungal suspension $(40 \mu \mathrm{L})$ and nutrient solution $(40 \mu \mathrm{L})$ were added. After incubation, the minimum inhibitory concentration (MIC) was taken as the lowest concentration of the test compounds in the wells of the 96-well plate in which the lowest microbial growth could be measured at $600 \mathrm{~nm}$. All tests were also carried out in triplicate.

\section{Results}

\section{Antimicrobial effect of the crude extracts of endophytic strains}

Bioassay results indicated that all crude extracts of endophytic strains had no antimicrobial activities against $E$. coli and $C$. albicans at the concentrations ranging from 0.1 to $10 \mathrm{mg} / \mathrm{mL}$ (Table I). However, they possessed various inhibitory effects on S. aureus. Especially, strains L1 and R1 showed stronger inhibitory effects than those of other endophytic strains and the positive control ampicillin sodium (Figure 1). Strain L9 cultured in salted PDB also exhibited moderate inhibitory effect on $S$. aureus at $10 \mathrm{mg} / \mathrm{mL}$. Furthermore, strain L1 still exhibited potent inhibitory effect at the lowest concentration of $0.1 \mathrm{mg} / \mathrm{mL}$, which suggested that L1 would a potential source for novel antibiotics.

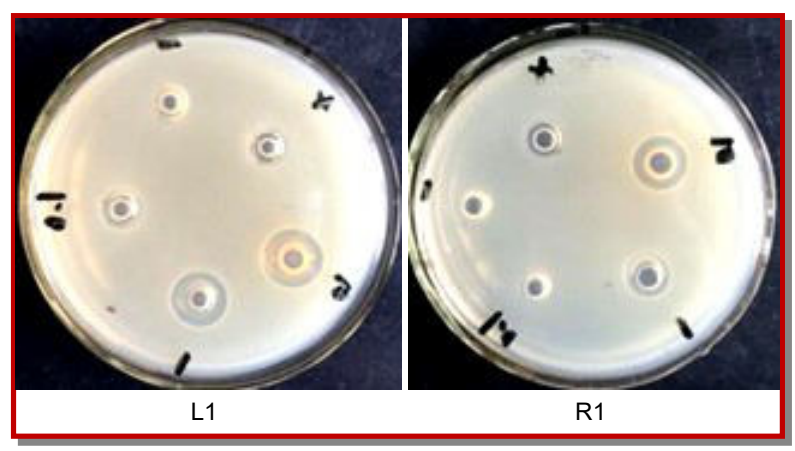

Figure 1: Inhibitory effect of crude extracts of endophytic strains $\mathrm{L} 1$ and R1 on S. aureus

Negative control (DMSO); +: positive control (ampicillin sodium); 10, 1, 0.1: concentration of crude EtOAc extract $(\mathrm{mg} / \mathrm{mL})$

\section{Identification of strains L1 and R1}

On basis of morphological characters of mycelium as well as spores characteristics grown on five culture media including PDA medium, corn meal agar (CMA), carrot agar (CA), Winogradsky's salt-solution agar (WSA) and plate count agar (PCA), strains L1 and R1 were preliminarily identified. Strain L1 grew slowly at the beginning of cultivation. Its colony gradually changed from white into pale yellow followed by light black and its hyphae was spindly, twining, and mostly branched (Figure 2), which was very similar to 
Table I

\section{Antimicrobial activities of ethyl acetate extracts of endophytic fungi from $R$. madaio}

\begin{tabular}{|c|c|c|c|c|}
\hline \multirow[t]{2}{*}{ Strain No. } & \multirow[t]{2}{*}{ Concentration $(\mathrm{mg} / \mathrm{mL})$} & \multicolumn{3}{|c|}{ Antimicrobial effecta } \\
\hline & & E. coli & S. aureus & C. albicans \\
\hline \multirow[t]{3}{*}{ L1 } & 0.1 & - & + & - \\
\hline & 1.0 & - & ++ & - \\
\hline & 10.0 & - & +++ & - \\
\hline \multirow[t]{3}{*}{ L1 (with salt) } & 0.1 & - & - & - \\
\hline & 1.0 & - & - & - \\
\hline & 10.0 & - & - & - \\
\hline \multirow[t]{3}{*}{ L6 } & 0.1 & - & - & - \\
\hline & 1.0 & - & - & - \\
\hline & 10.0 & - & ++ & - \\
\hline \multirow[t]{3}{*}{ L6 (with salt) } & 0.1 & - & - & - \\
\hline & 1.0 & - & - & - \\
\hline & 10.0 & - & ++ & - \\
\hline \multirow[t]{3}{*}{ L9 } & 0.1 & - & - & - \\
\hline & 1.0 & - & - & - \\
\hline & 10.0 & - & - & - \\
\hline \multirow[t]{3}{*}{ L9 (with salt) } & 0.1 & - & - & - \\
\hline & 1.0 & - & + & - \\
\hline & 10.0 & - & ++ & - \\
\hline \multirow[t]{3}{*}{ L10 } & 0.1 & - & - & - \\
\hline & 1.0 & - & + & - \\
\hline & 10.0 & - & ++ & - \\
\hline \multirow[t]{3}{*}{ L10 (with salt) } & 0.1 & - & - & - \\
\hline & 1.0 & - & - & - \\
\hline & 10.0 & - & ++ & - \\
\hline \multirow[t]{3}{*}{ R1 } & 0.1 & - & - & - \\
\hline & 1.0 & - & ++ & - \\
\hline & 10.0 & - & +++ & - \\
\hline \multirow[t]{3}{*}{ R1 (with salt) } & 0.1 & - & - & - \\
\hline & 1.0 & - & - & - \\
\hline & 10.0 & - & ++ & - \\
\hline \multirow[t]{3}{*}{ R2 } & 0.1 & - & - & - \\
\hline & 1.0 & - & - & - \\
\hline & 10.0 & - & ++ & - \\
\hline \multirow[t]{3}{*}{ R2 (with salt) } & 0.1 & - & - & - \\
\hline & 1.0 & - & + & - \\
\hline & 10.0 & - & ++ & - \\
\hline Ampicillin sodium & $30 \mu \mathrm{g} /$ disk & ++ & ++ & - \\
\hline Amphotericin B & $30 \mu \mathrm{g} /$ disk & - & - & +++ \\
\hline DMSO & - & - & - & - \\
\hline
\end{tabular}


morphological characters of Colletotrichum genus (Wei, 1979). Amplification of its genomic DNA by forward primer NS1-GTAGTCATATGCTTGTCTC and reverse primer NS6-GCATCACAGACCTGTTATTGCCTC afforded $1679 \mathrm{bp}$ fragments. Its $18 S$ rRNA sequence was analyzed using nucleotide BLAST software of NCBI and submitted to GenBank in NCBI and an accession number MF376146 was obtained (https:// www.ncbi.nlm.nih.gov/nuccore/MF376146). The phylogenetic tree was carefully built using MEGA 6.0 adjacency method and sequence analysis results revealed $99 \%$ similarity with that of Colletotrichum coccodes AJ301957.1 (Figure 2).

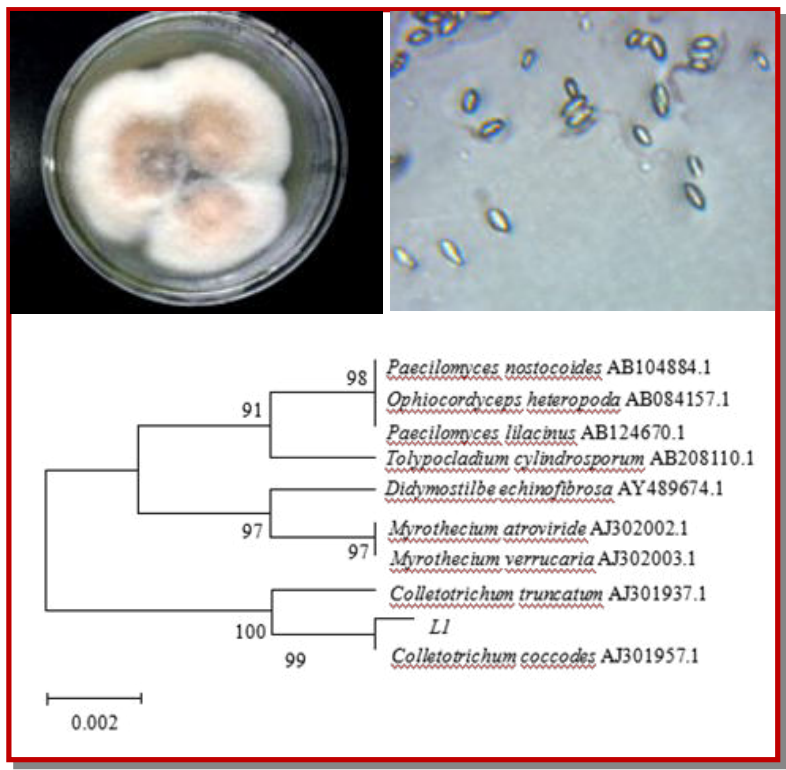

Figure 2: Morphological characteristics and phylogenetic tree of strain L1

Strain R1 grown on PDA medium quickly produced growing flesh colonies, white aerial mycelium, and fusiform conidia (Figure 3), which was very similar to morphological characters of Fusarium genus (Wei, 1979). Its $18 S$ rRNA with 1613 bp was obtained through amplification using the same primers described above and submitted to GenBank in NCBI and an accession number MF376147 had been acquired (https:// www.ncbi.nlm.nih.gov/nuccore/MF376147). Sequence alignment showed that strain R1 revealed 99\% identity with that of Fusarium oxysporum JF807402.1 (Figure 3). Therefore, on basis of their morphological properties and $18 S$ rRNA sequence analysis, endophytic strains L1 and R1 were respectively assigned to Colletotrichum and Fusarium geni.

\section{Structure elucidation of secondary metabolites from strain R1}

Bioassy-guided fractionation of the fermentation crude of strain R1 lead to isolation of two compounds $\mathbf{1}$ and 2 using HPLC method. By a combination of their 1D NMR and ESI-MS data as well as comparison with

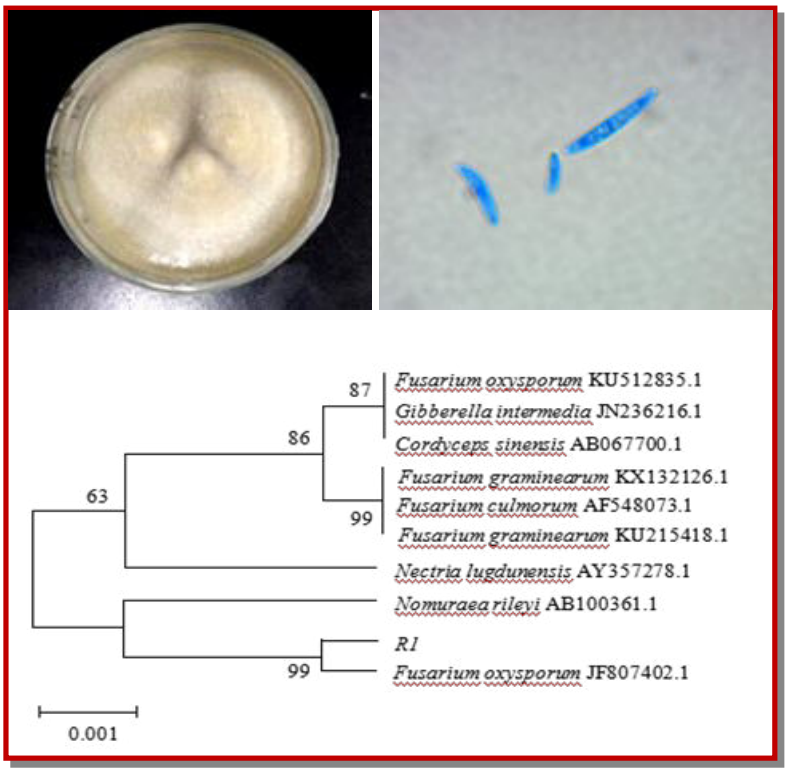

Figure 3: Morphological characteristics and phylogenetic tree of strain R1

literature, compounds $\mathbf{1}$ and $\mathbf{2}$ were respectively characterized as dibutyl phthalate (Wu et al., 2017), beauvericin (Zhang et al., 2016) (Figure 4). And the yield of compound 1 was about $1.17 \mathrm{mg} / \mathrm{L}$ while that of compound 2 was $2.5 \mathrm{mg} / \mathrm{L}$.

Dibutyl phthalate (1): White powder; $\mathrm{C}_{16} \mathrm{H}_{22} \mathrm{O}_{4} ;$ m.p. -35 ${ }^{\circ} \mathrm{C}$; ESI-MS (positive): $\mathrm{m} / \mathrm{z} 279[\mathrm{M}+\mathrm{H}]^{+}, 301[\mathrm{M}+\mathrm{Na}]^{+}$;

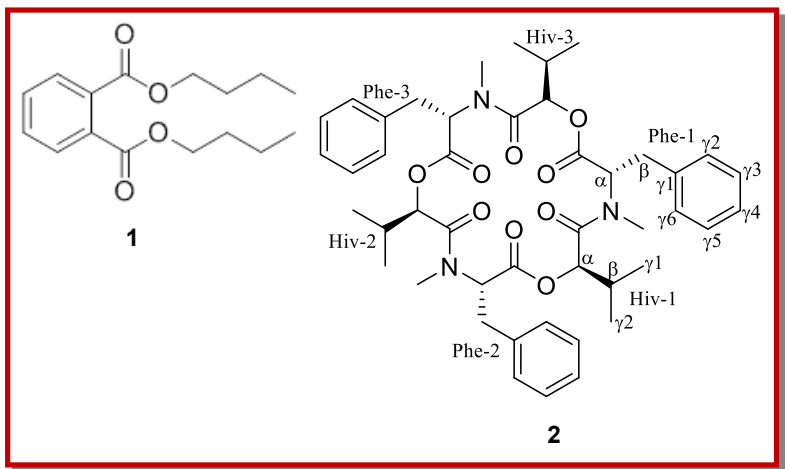

Figure 4: Chemical structures of antimicrobial compounds 1 and 2 from strain R1

${ }^{1} \mathrm{H}$ NMR (500 MHz, $\left.\mathrm{CDCl}_{3}, \delta, \mathrm{ppm}\right): 7.72(2 \mathrm{H}, \mathrm{m}, \mathrm{H}-3$, 6), 7.54 (2H, m, H-4, 5), 0.97 (6H, m, H-5', 5"), 1.44 (4H, m, H-4', 4"), 1.72 (4H, m, H-3', 3"), 4.31 (4H, t, H-2', 2").

Beauvericin (2): White acicular crystals; m.p. 93-94 ${ }^{\circ} \mathrm{C}$; ESI-MS (positive): m/z $806[\mathrm{M}+\mathrm{Na}]^{+}, 645,545,384$; $\mathrm{C}_{45} \mathrm{H}_{57} \mathrm{~N}_{3} \mathrm{O}$; ${ }^{1} \mathrm{H}$ NMR (500 $\left.\mathrm{MHz}, \mathrm{CDCl}_{3}, \delta, \mathrm{ppm}\right)$ : Hiv: $0.39(3 \mathrm{H}, \mathrm{d}, \mathrm{H}-\gamma 1), 0.80$ (3H, d, H- 2$), 1.97$ (1H, m, H- $\beta)$, $5.57(1 \mathrm{H}, \mathrm{d}, \mathrm{H}-\mathrm{\alpha})$; Phe: $3.02\left(3 \mathrm{H}, \mathrm{s}, \mathrm{H}-\mathrm{N}-\mathrm{CH}_{3}\right), 4.87(1 \mathrm{H}$, d, H-a), 1.98 (2H, dd, H- $\beta)$; ${ }^{13} \mathrm{C}$ NMR $\left(500 \mathrm{MHz}, \mathrm{CDCl}_{3}\right.$,

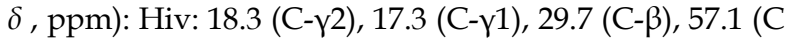


-a), 169.8 (C-CO); Phe: $32.13\left(\mathrm{C}-\mathrm{N}-\mathrm{CH}_{3}\right), 128.54$ (C-ү6),

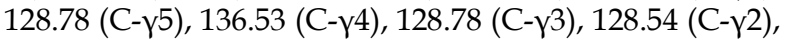

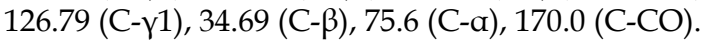

A number of endophytic strains had been reported to produce antimicrobial substances, such as beauvericin from F. oxysporum 5-19 colonizing in E. chrysantha L. (Zhang et al., 2016), colletonoic acid from Colletotrichum sp. endophytic on Umbelliferae (Tianpanich et al., 2011; Hussain et al., 2014). Dibutyl phthalate possessed a broad spectrum of antimicrobial activity (Roy et al., 2006), including inhibitory effect on E. coli and S. aureus with the same MIC value of $37.5 \mu \mathrm{g} / \mathrm{mL}$ (Rajamanikyam et al., 2017). Compound 2 had remarkable effect on two Gram-negative strains (Bacillus cereus and Salmonella typhimurium) with respective MIC values of 3.12 and $6.25 \mu \mathrm{g} / \mathrm{mL}$ (Dzoyem et al., 2017). In the present work, bioassay results indicated that dibutyl phthalate (1) had no inhibitory effect on three testing pathogenic strains, while beauvericin (2) exhibited the strongest antimicrobial activity against $E$. coli and $S$. aureus with MIC values of $62.5,3.9 \mu \mathrm{M}$, respectively.

\section{Discussion}

A number of endophytic strains had been reported to produce antimicrobial substances, such as beauvericin from F. oxysporum 5-19 colonizing in E. chrysantha L. (Zhang et al., 2016), colletonoic acid from Colletotrichum sp. Associated with Umbelliferae (Tianpanich et al., 2011; Hussain et al., 2014). Dibutyl phthalate (DBP) possessed a broad spectrum of antimicrobial activity against E. coli and S. aureus with the same MIC value of $37.5 \mu \mathrm{g} / \mathrm{mL}$ (Roy et al., 2006; Rajamanikyam et al., 2017). Beauvericin 2 was found to have remarkable inhibitory effect on two Gram-negative strains (Bacillus cereus and Salmonella typhimurium) with respective MIC values of 3.12 and $6.25 \mu \mathrm{g} / \mathrm{ml}$ (Dzoyem et al., 2017). In the present work, bioassay results indicated that DBP (1) had no inhibitory effect on three testing pathogenic strains, while beauvericin (2) exhibited the strongest antimicrobial activity against $E$. coli and $S$. aureus with MIC values of $62.5,3.91 \mu \mathrm{M}$, respectively. Fungal strains (L1, L6, L9, L10, R1, R2) from $R$. madaio possessed selectively inhibitory effects on $S$. aureus but no activity against $E$. coli or $C$. albicans. It may be ascribes to inappropriate fermentation factors for producing bioactive secondary metabolites. Chemodiversity of endophyteic microbes is associated with their cultivation conditions, such as incubation temperature, medium composition, degree of aeration, etc (Hewage et al., 2013; Yadav et al., 2016). Therefore, more effort should be made on isolation and identification of more antimicrobial chemicals from $R$. madaio-derived endophytes using the one strain-many compounds (OSMAC) approach (Gubiani et al., 2016; Hemphill et al., 2017).

\section{Conclusion}

Isolation of endophytic fungi from $R$. madaio and antimicrobial evaluation of their culture extracts for the first time led to the discovery of two bioactive fungal strains L1 and R1, which were respectively classified as Colletotrichum and Fusarium by analysis of their morphological characteristics and $18 S$ rRNA sequence. Chemical investigation of strain R1 resulted in isolation of two known antimicrobial agents, dibutyl phthalate (1) and beauvericin (2), which have potential application in pharmaceutical industry.

\section{Acknowledgement}

Financial supports from the National Key R \& D Program of China (2018YFC0311004 and 2017YFE0103100), the National Natural Science Foundation of China (41776139 and 81773628) and the Hangzhou Science \& Technology Development Program of China (20170432B02) were greatly appreciated.

\section{Supplementary Materials}

${ }^{1} \mathrm{H}$ - and ${ }^{13} \mathrm{C}$ NMR spectra, and positive ESI-MS spectra for compounds 1 and 2.

\section{Conflict of Interest}

The authors declare no conflict of interests.

\section{References}

Akay S, Ekiz G, Kocabas F, Hames-Kocabas EE, Korkmaz KS, Bedir E. A new 5,6-dihydro-2-pyrone derivative from Phomopsis amygdali, an endophytic fungus isolated from hazelnut (Corylus avellana). Phytochem Lett. 2014; 7: 93-96.

de Siqueira KA, Brissow ER, dos Santos JL, White JF, Santos FR, de Almeida EG, Soares MA. Endophytism and bioactivity of endophytic fungi isolated from Combretum lanceolatum Pohl ex Eichler. Symbiosis 2017; 71: 211-22.

de Siqueira VM, Conti R, de Araújo JM, Souza-Motta CM. Endophytic fungi from the medicinal plant Lippia sidoides Cham. and their antimicrobial activity. Symbiosis 2011; 53: 89-95.

Dhankhar S, Dhankhar S, Yadav JP. Investigating antimicrobial properties of endophytic fungi associated with Salvadora oleoides Decne. Anti-Infective Agents. 2013; 11: 49-59.

Dzoyem JP, Melong R, Tsamo AT, Maffo T, Kapche DGWF, Ngadjui B, Mcgaw LJ, Eloff JN. Cytotoxicity, antioxidant and antibacterial activity of four compounds produced by an endophytic fungus Epicoccum nigrum, associated with Entada abyssinica. Rev Bras Farmacogn. 2017; 27: 251-53.

Gubiani JR, Habeck TR, Chapla VM, Silva GH, Bolzani VS, Araujo AR. One strain-many compounds (OSMAC) method for production of phenolic compounds using Camarops sp., an endophytic fungus from Alibertia macrophylla (Rubiaceae). 
Quim Nova. 2016; 39: 1221-24.

Hemphill CFP, Sureechatchaiyan P, Kassack MU, Orfali RS, Lin WH, Daletos G, Proksch P. OSMAC approach leads to new fusarielin metabolites from Fusarium tricinctum. J Antibiot. 2017; 70: 726-32.

Hewage RT, Aree T, Mahidol C, Ruchirawat S, Kittakoop P. One strain-many compounds (OSMAC) method for production of polyketides, azaphilones, and an isochromanone using the endophytic fungus Dothideomycete sp. Phytochemistry 2014; 108: 87-94.

Hussain $\mathrm{H}$, Root N, Jabeen F, AI-Harrasi F, AI-Rawahi A, Ahmad M, Hassan Z, Abbas G, Mabood F, Shah A, Badshah A, Khan A, Ahmad R, Green IR, Draeger S, Schulz B, Krohn K. Seimatoric acid and colletonoic acid: Two new compounds from the endophytic fungi, Seimatosporium sp. and Colletotrichum sp. Chin Chem Lett. 2014; 25: 1577-79.

Islam R, Abay I. Research progress in Rumex obtusifolius L. Sci Technol Rev. 2013; 31: 67-71.

Kumar S, Nei M, Dudley J, Tamura K. MEGA: A biologistcentric software for evolutionary analysis of DNA and protein sequences. Brief Bioinform. 2008; 9: 299-306.

Li G, Kusari S, Kusari P, Kayser O, Spiteller M. Endophytic Diaporthe sp. LG23 produces a potent antibacterial tetracyclic triterpenoid. J Nat Prod. 2015; 78: 2128-32.

Liu Y, Li Y, Liu Z, Li L, Qu J, Ma S, Chen R, Dai J, Yu S. Sesquiterpenes from the endophyte Glomerella cingulata. J Nat Prod. 2017; 80: 2609-14.

Rajamanikyam M, Vadlapudi V, Parvathaneni SP, Koude D, Sripadi P, Misra S, Amanchy R, Upadhyayula SM. Isolation and characterization of phthalates from Brevibacterium mcbrellneri that cause cytotoxicity and cell cycle arrest. EXCLI J. 2017; 16: 375-87.

Rani R, Sharma D, Chaturvedi M, Yadav JP. Antibacterial activity of twenty different endophytic fungi isolated from Calotropis procera and time kill assay. Clin Microbiol. 2017; 6: 3.

Roy RN, Laskar S, Sen SK. Dibutyl phthalate, the bioactive compound produced by Streptomyces albidoflavus 321.2. Microbiol Res. 2006; 161: 121-26.

Santos SN, Ferraris FK, de Souza AO, das Graças Henriques M, Melo IS. Endophytic fungi from Combretum leprosum, with potential anticancer and antifungal activity. Symbiosis 2012; 58: 109-17.

Tianpanich K, Prachya S, Wiyakrutta S, Mahidol C, Ruchirawat S, Kittakoop P. Radical scavenging and antioxidant activities of isocoumarins and a phthalide from the endophytic fungus Colletotrichum sp. J Nat Prod. 2011; 74: 79-81.

Wang WX, Kusari S, Laatsch H, Golz C, Kusari P, Strohmann C, Kayser O, Spiteller M. Antibacterial azaphilones from an endophytic fungus, Colletotrichum sp. BS4. J Nat Prod. 2016; 79: 704-10.
Wang YJ. Inhibitory activity screening of endophytic fungi from Polygala tenuifolia Willd. Microbiology 2009; 36: 404-11.

Wei JC. Handbook of fungus classification. Shanghai Science and Technology Press, 1979.

Wu J, Liu Z, Su J, Lu H, Liao D, Song Q. Chemical constituents of the seahorse Hippocampus trimaculatus from East China Sea. Chem Nat Compd. 2017; 53: 982-83.

Yadav M, Yadav A, Kumar S, Sharma D, Yadav JP. Evaluation of in vitro antimicrobial potential of endophytic fungi isolated from Eugenia jambolana Lam. Int J Pharm Pharm Sci. 2014; 6: 208-211.

Yadav M, Yadav A, Kumar S, Yadav JP. Spatial and seasonal influences on culturable endophytic mycobiota associated with different tissues of Eugenia jambolana Lam. and their antibacterial activity against MDR strains. BMC Microbiology. 2016; 16: 44.

Zhang H, Bai X, Wu B. Evaluation of anti-microbial activities of extracts of endophytic fungi from Artemisia annua Linn. Bangladesh J Pharmacol. 2012; 7: 120-23.

Zhang H, Bai X, Zhang M, Chen J, Wang H. Bioactive natural products from endophytic microbe. Nat Prod J. 2018; 8: 86108.

Zhang H, Crews P, Tenney K, Valeriote FA. Cytotoxic phyllactone analogs from the marine sponge Phyllospongia papyrecea. Med Chem. 2017; 13: 295-300.

Zhang H, Ruan C, Bai X, Zhang M, Zhu S, Jiang Y. Isolation and identification of the antimicrobial agent beauvericin from the endophytic Fusarium oxysporum 5-19 with NMR and ESI-MS/MS. Biomed Res Int. 2016; 2016: 1084670.

Zhang H, Ying C, Bai X. Advancement in endophytic microbes from medicinal plants. Int J Pharm Sci Res. 2014b; 5: 1589_ 600

Zhang HW, Song YC, Tan RX. Biology and chemistry of endophytes. Nat Prod Rep. 2006; 23: 753-71.

Zhang HW, Ying C, Tang YF. Four ardeemin analogs from endophytic Aspergillus fumigatus SPS-02 and their reversal effects on multidrug-resistant tumor cells. Chem Biodivers. 2014a; 11: 85-91.

Zheng YK, Qiao XG, Miao CP, Liu K, Chen YW, Xu LH, Zhao LX. Diversity, distribution and biotechnological potential of endophytic fungi. Ann Microbiol. 2016; 66: 529-42.

Zhou XM, Zheng CJ, Chen GY, Song XP, Han CR, Li GN, Fu YH, Chen WH, Niu ZG. Bioactive anthraquinone derivatives from the mangrove-derived fungus Stemphylium sp. 33231. J Nat Prod. 2014a; 77: 2021-28.

Zhou ZF, Kurtan T, Yang XH, Mandi A, Geng MY, Ye BP, Taglialatela-Scafati O, Guo YW. Penibruguieramine A, a novel pyrrolizidine alkaloid from the endophytic fungus Penicillium sp. GD6 associated with Chinese mangrove Bruguiera gymnorrhiza. Org Lett. 2014b; 16: 1390-93.

\begin{tabular}{l|} 
Author Info \\
Huawei Zhang (Principal contact) \\
e-mail: hwzhang@zjut.edu.cn
\end{tabular} 